\section{Chairside teaching and the perceptions of dental teachers in the UK}

\author{
J. Sweet, ${ }^{1}$ J. Wilson ${ }^{2}$ and L. Pugsley ${ }^{3}$
}

VERIFIABLE CPD PAPER
IN BRIEF

- Views on chairside teaching were elicited from dental tutors from around the UK.

- Dental tutors agreed that there should be educational training for all clinical teachers.

- Five categories of chairside teacher were identified: dental practitioner, senior academic, intuitive dental practitioner, teacher trained academic, and dental educational developer.

\begin{abstract}
This study outlines how dental tutors at the chairside view their teaching and describes what are considered important current issues, requirements and recommendations for good chairside teaching practice. A qualitative analysis was undertaken of stakeholder perceptions of chairside teaching from both a single dental school study and a UK wide evaluation workshop. The evaluation of good chairside teaching showed that training requirements might be quite different for different stakeholders in chairside teaching. Further, this evaluation process may serve as a process model for institutional change for improvements in chairside teaching. This article is the second of a series of three and evaluates chairside teaching on a UK wide scale. The first, investigated the perceptions of stakeholders of chairside teaching at a single dental school. The third provides educational tools to encourage collaboration and sharing good chairside teaching practice. A further accompanying article reviews some of the educational methodology and innovations in teaching and learning that may be applied to dentistry.
\end{abstract}

The aim of the study was to provide an overview of perceptions of chairside teachers in the UK. The first article in this series ${ }^{1}$ reported on the perceptions of stakeholders of chairside teaching at a single dental school. These were evaluated by dental colleagues invited from each UK

\section{PERCEPTIONS OF CHAIRSIDE TEACHING}

1. Stakeholder perceptions of chairside teaching and learning in one UK dental school

2. Chairside teaching and the perceptions of dental teachers in the UK

3. Tools to share good chairside teaching practice: a clinical scenario and appreciative questionnaire

4. Educational innovations for dentistry

${ }^{1 *}$ Associate Clinical Professor, Institute of Clinical Education, Warwick Medical School, Medical School Building, University of Warwick, Coventry, CV4 7AL; ${ }^{2}$ Senior Lecturer, School of Dentistry, Cardiff University, Heath Park, Cardiff CF14 4XY; ${ }^{3}$ Academic Unit of Postgraduate Medical and Dental Education, Wales College of Medicine, Biology, Life and Health Sciences, Cardiff University, Heath Park, Cardiff CF14 4XN

${ }^{*}$ Correspondence to: Mr John Sweet

Email: john.sweet@warwick.ac.uk

\section{Refereed Paper}

Accepted 16 July 2008

DOI: $10.1038 /$ sj.bdj.2008.983

British Dental Journal 2008; 205: 565-569 dental school, via the medical and dental subject centre of the Higher Education Academy, to a workshop conference held over two days. This paper describes the outcomes of a qualitative analysis (described in the accompanying education innovation paper in this series).

\section{Review of chairside literature}

Surprisingly little information is available on how early clinical experience and the presence of relatively inexperienced students in a dental clinic impacts on clinical teaching or how clinical teaching has had to adapt to various cohorts of students with different education experiences and expectations. Unlike research, where often a problem can be exploited as a useful starting point for a range of investigations that can later be published, problems in teaching can be interpreted as failure and generally avoided, or at best, solved quickly so that trouble free teaching may resume as quickly as possible. Issues are therefore rarely published. Lawton ${ }^{2}$ was one of the first authors to admit that undergraduate chairside teaching might not be what it could be and made suggestions for improvements:

1) Providing qualified dental nurse assistance to provide better learning and a more efficient use of time. (Nixon and Rowbotham ${ }^{3}$ had already reported successful early attempts at teaching chairside assistance for fourhanded dentistry to dental students, who were otherwise taught to work alone)

2) Introducing 'vertical podding' - student group practices consisting of students from each level of the course with the necessary nursing and dental tutor support, following the suggestions of Gilmore ${ }^{4}$ and Bellanti ${ }^{5}$ to aid better student/patient allocation matching. Patients with more complex treatment needs could be allocated to senior students and those with simple needs to junior students.

However, 30 years later, dental students were still working without nursing support at a London dental school, so Bartlett and Woolford ${ }^{6}$ were able to show students similar praise for working in a dental team with full nursing support in an outreach clinic.

Mullins and Wetherall ${ }^{7}$ describe how they ask dental students to be explicit about their expectations of their clinical educators and how a trusting learning 
environment can be optimised in the dental teaching clinic. Also they have applied modern educational theory to dental practice at Adelaide Dental School. ${ }^{8}$ Powell and Barrett ${ }^{9}$ emphasise the fact that part-timers outnumber full time faculty teaching clinical dentistry and describe the benefit of in-service training. The case for training dental tutors in dental schools has been made by Carrotte ${ }^{10}$ but detailed evidence has not been forthcoming either in terms of deficiencies in provision, or in the range of excellent practices that could be shared. Either or both of these could justify an educational enhancement training programme. The beginnings of such evidence may be forthcoming as Behar-Horenstein et al. ${ }^{11}$ were disappointed in finding that critical thinking skills were infrequently taught at the chairside and this underscored the need they perceived for periodic appraisal of clinical instruction.

\section{Materials and methods}

Two complementary methods of qualitative analysis were used. The first was an analysis of the findings of a representative group made up largely of chairside teachers who were able to use their own experiences, and the reported findings of the perceptions of chairside teachers at a single dental school, as a baseline for their own evaluation of chairside teaching. The second was an in-depth analysis undertaken by the authors, which attempts, at an impersonal level, to place people's conceptions of the world into different categories to gain a general understanding. The first approach collects individual conceptions to gain consensus whilst the other seeks to find major differences in approach that would separate out conceptions of one group from another. In this way, the overall picture of the challenging issues involved in chairside teaching is identified. But, in addition, the possible differing roles of different dental tutors to support, change and improve chairside teaching can be made.

\section{Evaluation methodology}

Overview

Representative chairside teachers from dental schools throughout the UK

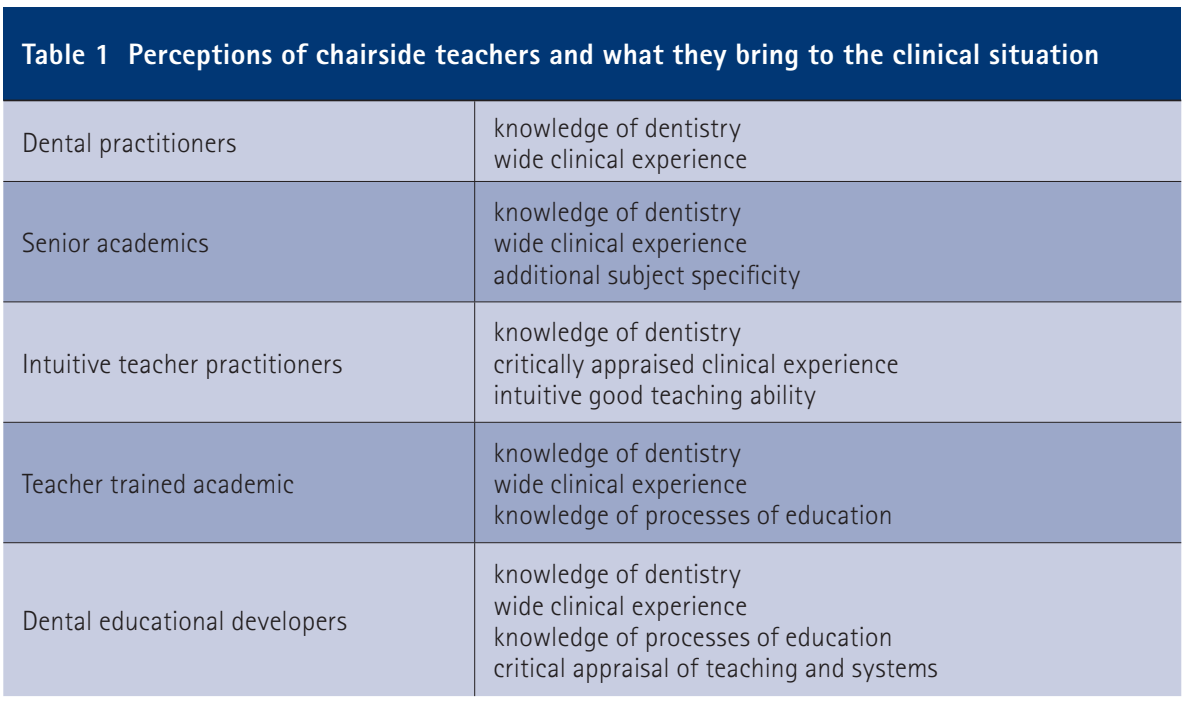

attended a two day conference/workshop $^{12}$ where the authors led a dedicated strand on evaluating chairside teaching and presented their research findings based on semi-structured interviews conducted with clinical teachers at one UK dental school (reported in part 1 of this series). The response of the participants was recorded, transcribed and an interpretive analysis made.

\section{Details}

The participants of the evaluation workshop were introduced to a number of complementary approaches used in a sequence to help them produce a rounded critical evaluation. ${ }^{13}$ Participants were first given the opportunity to independently identify issues of importance in nurturing good chairside teaching in practical terms from their own personal experience and that within their organisation. ${ }^{14}$ They were also able to discuss ideals to aim for and also what they thought were severe barriers to successful chairside teaching. ${ }^{15}$ At this point the dental school findings ${ }^{1}$ were presented, and from this colleagues were able to calibrate this single school's chairside teaching situation against their views on chairside teaching at their own institutions, thereby determining whether the findings from the single school are common throughout the UK.

\section{Results: evaluation results and initial reflections}

The participants at the workshop were first given the opportunity to identify what they thought were vital issues for successful chairside teaching. Despite the wide-ranging backgrounds and roles of the participants they reached a consensus that the following were the most important issues:

1) Quality control of chairside teaching

2) Educational training in teaching for all chairside teachers, especially part-time general dental practitioners

3) Encourage interactive skills of dental tutors facilitating student learning in the clinic

4) Ensure optimised student/staff ratios

5) Ensure the continuity of teaching - avoiding changing treatment plans

6) Provision of standardised protocols, where all teaching follows these closely

7) Ensure good feedback to students - which ideally should be immediate, and to be sensitive to different student learning styles.

Overall, there was a sense that chairside teaching could improve if it was given better recognition and that a high profile research agenda for clinical academics was generally a negative influence.

\section{Transferability of the single site findings}

Following the presentation of dental school findings ${ }^{1}$ the workshop participants were able to discuss in detail the themes that were of importance that arose there with the issues that they had independently generated themselves. The dental school data appeared in general terms to be representative. Similarities 
were seen between all six other UK dental schools represented in the workshop. They could confirm that their chairside teaching was similar to the study dental school in that:

1) Chairside teaching is traditionally carried out on a one-to-one basis between dental tutor and dental student

2) Most teaching is carried out by staff who are untrained and teaching standards are variable

3) Perceptions of chairside teaching of dental tutors, and dental students and dental nurses is likely to be different

4) Use of peer and interprofessional education options are generally neglected

5) Staff student ratios are not ideal

6) There is scope for greater use of media and technology

7) There is scope for the empowerment of patients

8) A number of useful innovations are taking place at all schools.

The evaluation confirmed three main requirements for good chairside teaching:

1) Good educational practice - understanding how students learn in the dental clinic and help to support their learning

2) Good teacher logistics and training -- understanding the individual educational development needs of dental tutors and offering suitable training programmes

3) Good clinical organisation - understanding of innovative modes of practice, clinic organisation and sharing good practice.

In addition, improvements in technology, innovation in teaching and assessment and practice of an appreciative quality evaluation could have positive impacts on all three of these requirements. Opportunities should be taken to develop all these approaches. The evaluation consistently rejected ideas of quotas and the need for mechanical repetition, and also 'teaching by humiliation' which was considered bad practice by all.

Based on a discussion of reflections and presentation findings the major recommendations were that:

1) Dental tutors should all have educational training in teaching

2) Dental schools should encourage peer review of teaching

3) Dental schools should encourage reflective practice

4) Chairside teaching should be subject to quality control and enhancement

5) Collaborative networks to develop good teaching practice should be encouraged across institutions.

\section{In-depth methodology}

All the collected data from the single dental school study ${ }^{1}$ and the subject centre workshop outlined above was subject to a form of reflective in-depth analysis (see the accompanying education innovation paper).

\section{Results from the in-depth analysis}

\section{Perceptions}

From the analysis of interviews and transcriptions it was clear that there were distinct variations in the contributions that different staff could make to chairside teaching, understanding teaching development needs and acting on them. From the analysis it became clear from the data that five categories of chairside teacher could be differentiated and these are outlined in Table 1.

Table 1 summarises the characteristics of the different teacher types and what they specifically bring to the clinical situation. From the table it can be seen that there is a gradual increase in complexity towards the dental educational developer. However, all categories in the list bring something very special to the chairside, which may or may not be possessed by the educational developer. But, without the educational development approach there is not the educational vision or impetus for change and improvement that can lead to improvement in chairside teaching.

\section{Dental practitioners}

Clearly, many part-time practitioners have a major focus elsewhere but many bring much in the way of experience and knowledge into the dental clinic teaching. In fact some think of their job as 'at the coalface' and see their position as one who helps students by example and as role models. They tend to see their role as one to supervise rather than to teach. However, when asked about student learning they often equated this with what the students were taught in the school.

'You develop a way of talking to a patient and describing to a patient what you are trying to achieve so logically you can use that skill to talk to the students and describe to them what they need to achieve - what the patient requires and so on.'

'I think there are some special cases where it is particularly useful to know how to do something like a lower left molar crown preparation. You're not going to learn that on a bridge course. I've learned the hard way so I have some interesting techniques to offer. Things I picked up from messing it up myself and repeating it so many times.'

\section{Senior academics}

Senior academics show an emphasis on covering the syllabus and getting the students organised. Their own perceived inherent intuitive greatness could be something of a block to communication with junior staff or students. They tend to be resistant to change especially that which involves modern teaching methodologies or threatens authority of the discipline.

'I try to instil organisation - professionalism - doing the right thing at the right time.'

'I think it would be very unfair to expect the undergraduates to teach or assess themselves - why should a fourthyear student have to explain to a secondyear student when it could be explained by members of staff.'

'If we had DCPs attached to each dental student group that would be marvellous but unrealistic.'

\section{Intuitive teacher practitioners}

These practitioners show an emphasis on practical learning and common sense thought and have a clear idea of seeing students through from one learning experience to another. They are aware of many issues beyond their control and ask for clear guidance on what should be taught. 
'Enlightening - that people have got similar views is great - I would like to see a more seamless margin between the inhospital teaching and the outreach teaching - not to change us all into academics but have some teaching or training course which will make it more uniform teaching across the board.'

\section{Teacher trained academics}

Teacher trained academics are keen to stimulate critical thinking and want to apply a range of education theory which they experienced in their courses. They want standardised guidelines for procedures and quality control measures and are keen to promote reflective practice

'Teaching people to evaluate and to give feedback is of great importance and should be basic training.'

'Students - once they start to think for themselves they start learning rather than tell show do-develop critical thinking.'

\section{Educational developers}

Educational developers are dental teachers with a mission to change chairside teaching and have clear views on problems of chairside teaching. They want to apply a range of educational theory to bear on chairside teaching and are full of ideas to improve teaching such as inter year activity to promote learning. They are interested in promoting team working and interprofessional education. They are keen to promote university-based action to encourage educational training programmes for clinical teachers and to encourage universities to develop career pathways.

'Two things - my resolution is to get myself on a change management course -you end up with all these ideas but to go back and get the staff to accept it - I think that is a real skill and I don't think I have that at the moment.'

'The other thing is the old gripe that you cannot do everything to an extremely high standard - such a need for the universities to recognise that there needs to be expertise in the teaching arena - they need to recognise that and facilitate the appropriate career pathways -it is so sad that things are so slow to happen. Things are beginning to change.'

\section{Discussion}

It is clear that different clinicians have different approaches to chairside teaching based on their background and current teaching and practising position in dentistry. The evaluation workshop participants brought a whole range of perspectives to bear on the dental school findings presented to them with their own shared experiences. They contributed approaches from reviewing practical issues in dental practice and their impact on teaching to educational theory and a focus on contextualised situated learning. Despite these differing points of departure, it was possible to reach a consensus on all issues that were considered important.

This may serve as a model for further educational training and development where a dialogue between the dental tutor stakeholders in chairside teaching around focusing issues or themes may be of great value to the individual clinicians and to their institution's improvement of chairside teaching for its students. In the workshop described here, non-clinicians including a social linguist and educationalists from other fields in higher education, and a veterinary surgeon visited the group, joined and helped widen the context of the discussion. Clearly there would be opportunity to invite other stakeholders such as dental students and nurses, DCPs, patients and administrators to this kind of discussion where the agenda was to improve chairside teaching in a particular institution.

The five perceptions derived from the in-depth analysis indicate that dental teaching clinicians who tend to fall into any one of those categories may also benefit from specific educational training and professional development. General practitioners without sufficient training may unwittingly be straying from taught procedures, which may confuse students especially in the early years. They may be so submerged in their subject that they fail to recognise student-learning issues. Natural teachers without sufficient training have been called 'diamonds in the rough'. ${ }^{16}$ Without an education in teaching and sufficient self-reflection and peer feedback, some severe blind spots in teaching methodology may mar what is generally good teaching practice. The diamonds need polishing to become star teachers. ${ }^{16}$ Very often senior academics need to be more open and supportive of change and stop pulling back younger, educationally trained staff, with innovative ideas. Academics who are educationally trained need to ensure that they do not become brittle and inflexible in their educational approach and that they are continually maintaining a dialogue to improve their practice. Educational developers need to continue their professional development to ensure that their vision and approach is appropriate when acting as agents of change.

The value of categorising perceptions is that education and training may be aligned more closely to need and possible take-up. Recognising the categories also lead to the conclusion that optimal chairside teaching is dependent upon all dental tutor stakeholders continuing a vigorous continued programme of professional development. The value of the workshop findings is that they articulate important issues that are important for successful chairside teaching.

The five categories derived from the data from a single school study and a UK workshop, and the evaluation findings appraising chairside teaching, provide a staring point for further investigation and cross institutional collaboration.

1. Sweet J, Pugsley L, Wilson J. Stakeholder perceptions of dental chairside teaching and learning in one UK dental school. Br Dent J 2008; 205: 499-503

2. Lawton FE. What can be dome to correct deficiencies in the undergraduate course? Int Dent J 1976; 26: $67-72$.

3. Nixon G S, Rowbotham T C. Student teaching with chairside assistance. Br Dent J 1970; 129: 214-217.

4. Gilmore N D. Learning model for clinical dentistry. J Dent Educ 1973; 37: 35-38.

5. Bellanti N D, Wiggs J S, Kenney E B et al. Individualization of clinical dental curriculum. J Dent Educ 1973; 37: 33-36.

6. Bartlett D W, Woolford M. Team training at an outreach dental unit. Eur J Prosthodont Restor Dent 2003; 11: 133-135.

7. Mullins G, Wetherell J et al. Learning in the clinical environment. In Sweet J, Huttly S et al. (eds). Effective learning and teaching in medical dental and veterinary education, $1^{\text {st }}$ ed. pp 164-179. London: Kogan Page, 2003.

8. Mullins G, Wetherell J et al. Problem-based learning in dentistry: the Adelaide experience. Adelaide: University of Adelaide, 2001.

9. Powell G L, Barrett J E. Inservice Training for Parttime Dental Faculty. J Dent Educ 1981; 45: 68-70.

10. Carrotte PV. Educating the educators - do university lecturers require training in educational 
practice? Br Dent J 1994; 177: 217-220.

11. Behar-Horenstein LS, Dolan T A et al. Cultivating critical thinking in the clinical learning environment. J Dent Educ 2000; 64: 692-693.

12. Sweet J, Wilson, J, Pugley L. Evaluating Chairside Teaching strand in Breaking Boundaries 2005

- Innovation in healthcare education - Higher
Education Academy subject centre for Medicine Dentistry and Veterinary Medicine. Wednesday 9 November 2005.

13. Preskill H, Torres R T. Evaluative inquiry for learning in organisations. Thousand Oaks, California: Sage, 1999.

14. Scriven M. Evaluation thesaurus, 4th ed. Thousand
Oaks, California: Sage, 1991.

15. Patton M Q. Utilization-focussed evaluation, 3rd ed. v. The new century text. Thousand Oaks, California: Sage, 1997

16. Frase L, Hetzel R. School management by wandering around. Lancaster, Pennsylvania: Technomic, 1990.

\section{Erratum}

Stakeholder perceptions of chairside teaching and learning in one UK dental school (BDJ 2008; 205: 499-503)

It has been brought to our attention that in $B D J$ volume 205 issue 9, the above article in the education section contained errors in the author biography. Mr John Sweet's author biography should have read as follows:

\section{Associate Clinical Professor}

Institute of Clinical Education

Warwick Medical School

Medical School Building

University of Warwick

Coventry

CV4 7AL

Email: john.sweet@warwick.ac.uk

We apologise for any inconvenience caused. 